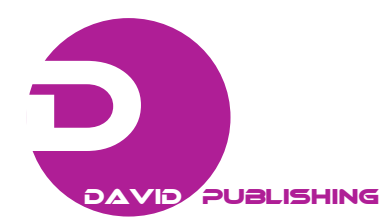

\title{
Food Hygiene 7S in Pest Control Examples
}

\author{
Tamio Kanayama \\ Engineering Department, TOYOSANGYO Co., Ltd, 3-19-20 shinyashiki-cho, Kita-ku, Okayama 700-0986, Japan \\ Corresponding author's e-mail: t-kanayama@to-yo-s.co.jp
}

\begin{abstract}
Food Hygiene 7S (Seiri-sorting out, Seiton-systematic arrangement, Seisou-sweep, Senjou-scrub, Sakkin-sanitation, Shitsuke-discipline, Seiketsu-cleanliness) is a management method to develop and maintain the "Cleanliness" of the food manufacturing. "Cleanliness" means not only clean to look at, but bacteria are non-existence or reduced to the level which will not suffer under the influence of food safety, and the object of Food Hygiene 7S is the cleanliness of microbial level. Food Hygiene 7S corresponds to the pre-requisite programs in HACCP or the PRP in ISO22000, and it's exactly the foundation to achieve food safety. In addition, activities based on Food Hygiene 7S make possible to control of insects and rodents, because sorting-out or systematic-arrangement deprives their hiding and living space, or setting the easy environment to sweep deprives their feed. If all of the engaged people carry on this activities at their workplaces, they will get visible effect, their attitude will change, and it will make continuous improvements at the manufacturing scene. So the authors explain cases and real impact of activities utilizing Food Hygiene 7S.
\end{abstract}

Key words: Food Hygiene 7S, management method, HACCP, ISO22000. 